\title{
KARAKTERISTIK KULTURAL DAN FILOSOFI MATEMATIKA
}

\author{
Ikhbariaty Kautsar Qadry ${ }^{1 *}$ \\ Syahrullah Asyari ${ }^{2}$ \\ Nur Ismiyati ${ }^{3}$ \\ Andi Patimbangi ${ }^{4}$ \\ ${ }^{1}$ Universitas Muhammadiyah Makassar, Makassar, Indonesia \\ ${ }^{2}$ Universitas Negeri Makassar, Makassar, Indonesia \\ ${ }^{3}$ Universitas Balikpapan, Balikpapan, Indonesia \\ ${ }^{4}$ Sekolah Tinggi Agama Islam Negeri Bone, Bone, Indonesia \\ $\frac{\text { ikhbariaty.qadry@unismuh.ac.id }{ }^{{ }^{*}}}{\text { syahrullah_math@unm.ac.id }}$
nurismiyati@uniba-bpn.ac.id
andipatimbangi85@gmail.com
}

\begin{abstract}
Abstrak
Penelitian ini adalah penelitian kepustakaan yang bertujuan mengkaji dua hal pokok. Pertama, karakteristik kultural matematika. Kedua, karakteristik filosofi matematika. Hasil penelitian menunjukkan bahwa karakteristik kultural matematika dapat dilihat dari sisi nilai dan praktik sosial matematika, maupun sisi konvensi matematika. Nilai kultural matematika dapat dilihat dari program etnomatematika. Sementara itu, praktik sosial matematika dapat dilihat dari Realistic Mathematics Education. Namun demikian, tetap diakui bahwa matematika memiliki karakteristik yang khas atau sifat alami sebagai suatu konvensi, sekaligus merupakan bagian dari karakteristik kultural matematika. Sementara itu, karakteristik filosofi matematika bergantung pada sudut pandang aliran-aliran filsafat tertentu terhadap matematika. Hasil rekonseptualisasi filsafat matematika menunjukkan bahwa suatu filsafat matematika mestinya memenuhi empat kriteria, yaitu: a) pengetahuan matematika: sifat, justifikasi dan genesisnya; b) obyek-obyek matematika: sifat dan asal-usulnya; c) aplikasi matematika: keefektifannya dalam sains, teknologi dan bidang-bidang lainnya; dan d) praktik matematika: berbagai aktivitas para matematikawan, baik di masa sekarang, maupun di masa lampau.
\end{abstract}

Kata Kunci: Etnomatematika, Filosofi matematika.

\section{Diterbitkan Oleh:}

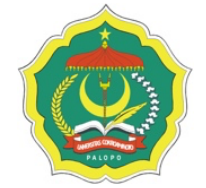

\author{
Fakultas Sains \\ Program Studi Matematika \\ Universitas Cokroaminoto Palopo
}

Copyright (C) 2021 The Author (s)

This article is licensed under CC BY 4.0 License

(cc) BY 


\section{KARAKTERISTIK KULTURAL DAN FILOSOFI MATEMATIKA}

\section{Pendahuluan}

Matematika adalah alat yang penting dalam pesatnya perkembangan sains, teknologi tinggi dan perniagaan di dunia saat ini (Skemp, 1987). Matematika adalah ilmu yang unik. Sejumlah referensi, baik buku maupun jurnal menyebutkan makna matematika dengan sudut pandangnya masing-masing.

Khait (2005) menyatakan, "Mathematics is an essentially linguistic activity characterized by association of words with precise meanings". Artinya, matematika adalah aktivitas linguistik esensial yang dicirikan oleh gabungan kata-kata (matematika) dengan makna yang tepat. Sementara itu, Skemp (1987) memandang matematika sebagai alat powerful yang terpusat pada pemfungsian inteligensi manusia, buah dari inteligensi manusia, dan cara menggunakan pikiran kita yang dapat meningkatkan kekuatan pikiran kita. Adapun menurut Johnson \& Rising (1967), matematika pada dasarnya berkenaan dengan ide-ide, proses-proses, dan penalaran. Dengan demikian, menurutnya, matematika jauh lebih dari sekadar aritmetika (ilmu tentang bilangan dan komputasi); lebih dari sekadar aljabar (bahasa simbol dan relasi); lebih dari sekadar geometri (studi tentang bentuk, ukuran dan ruang).

Uraian di atas menunjukkan bahwa matematika adalah ilmu yang memiliki banyak wajah, di mana tidak ada kesepakatan di antara para matematikawan tentang apa itu matematika (Johnson \& Rising, 1967; Hudojo, 1990; Soedjadi, 2000). Meskipun matematika tidak memiliki satu definisi tunggal dan disepakati oleh semua tokoh atau pakar matematika, kita dapat menyatakan bahwa matematika adalah kreasi pikiran manusia (Johnson \& Rising, 1967). Adapun bagi Soedjadi (2000) definisi yang berbeda-beda itu, bila didalami justru akan menunjukkan karakteristik tertentu yang dapat merangkum definisi matematika secara umum.

Artikel ini akan mengulas tentang karakteristik matematika. Karakteristik matematika dalam artikel ini ditinjau dari aspek kultural dan filosofi. Oleh karena itu, bahasan akan dimulai dengan aspek kultur matematika, kemudian aspek filsafat matematika. Setelah itu, meninjau karakteristik matematika berdasarkan uraian tentang kultur dan filsafat matematika.

\section{Metode Penelitian}

Penelitian ini adalah penelitian kepustakaan. Penelitian ini dilakukan pada Nopember 2020 sampai Maret 2021. Sumber data dalam penelitian ini adalah sumber sekunder. Elmer E. Rasmuson Library (2020) menyatakan bahwa sumber sekunder adalah hasil kajian dari peneliti 
lain. Sumber sekunder mendeskripsikan, menganalisis, dan/atau mengevaluasi informasi yang ditemukan pada sumber-sumber primer. Dengan mengemas kembali informasi, sumber sekunder membuat informasi menjadi lebih mudah diakses. Beberapa contoh sumber sekunder menurut Elmer E. Rasmuson Library (2020) adalah buku, artikel jurnal dan majalah, ensiklopedia, kamus, buku pegangan (handbook), indeks periodik (periodical indexes), hasil review dan lain-lain.

Dalam penelitian ini, sumber kami adalah buku, jurnal, prosiding, dan kamus. Penelitian ini dilakukan dengan tahapan menurut Elmer E. Rasmuson Library (2020) sebagai berikut. membatasi topik yang akan dibahas (defining the topic), menuliskan pernyaaan masalah (writing a thesis or problem statement), membuat pokok-pokok yang akan diuraikan (making an outline), mengembangkan strategi pencarian sumber (developing a search strategy), mengevaluasi sumber yang diperoleh (evaluating the sources), mencatat dengan cermat (taking careful notes), menulis dan merevisi paper (writing and revising the paper), dan mendokumentasikan sumber yang diperoleh (documenting the sources).

\section{Hasil dan Pembahasan}

\section{Makna Kultur Matematika}

Secara bahasa, kata "Kultur" diambil dari kata bahasa Inggris, "Culture". Menurut Merriam-Webster Dictionary (2020), "kultur" atau "culture" diartikan sebagai, "The set of values, conventions, or social practices associated with a particular field, activity, or societal characteristic”. Artinya, kultur adalah himpunan nilai, konvensi, atau praktik sosial yang berkaitan dengan bidang tertentu, aktivitas, atau karakteristik sosial.

Larvor (2016) mengemukakan bahwa, secara semantik, kata "kultur" kaya makna. Banyak makna kata "kultur". Menurutnya, secara umum, makna kata "kultur" dapat dibagi menjadi dua, yaitu makna normatif (edukatif) dan makna deskriptif (saintifik).

Secara normatif, mengacu pada pendapat Matthew Arnold, kultur adalah suatu proyek pendidikan. Setiap orang bisa dan mestinya memiliki proyek pendidikan. Bahkan, setiap orang bisa dan mestinya memperoleh manfaat dari proyek pendidikan.

Secara deskriptif, mengacu pada pendapat Kroeber \& Kluckhohn, kultur dinyatakan sebagai pola perilaku yang dinyatakan dan disebarkan melalui simbol dan artefak (papan tulis, notasi, diagram, model, dan komputer). Dari sudut pandang positivisme atau behaviorisme, definisi ini dapat diterima secara ilmiah. Simbol, artefak dan perilaku (menggerakkan anggota badan, menulis, membuat sketsa, mengumpulkan matematikawan dalam suatu wadah, dan lainlain) semuanya dapat ditemukan secara empiris. Namun demikian, para penganut positivisme 
atau behaviorisme menyatakan bahwa inti dari suatu kultur adalah, "ide, khususnya nilai yang melekat pada ide tersebut". Ide dan nilai tidak begitu mudah dideteksi secara empiris. Ide dan nilai mungkin dideteksi secara tidak langsung melalui efeknya atau pengaruhnya. Bagi Kroeber \& Kluckhohn, pusat nilai adalah antropologi. Maksudnya, "Nilai adalah satu-satunya basis yang sangat jelas untuk memahami kultur, karena pengorganisasian semua kultur yang ada pada dasarnya berkaitan dengan nilai.

Di atas telah diuraikan makna kultur. Dari makna secara bahasa dan istilah itu, kultur matematika dapat disebut sebagai himpunan nilai, konvensi, atau praktik sosial matematika yang bermanfaat bagi manusia.

\section{Gerakan Intelektual untuk Mengkaji Kultur Matematika}

Ada dua gerakan intelektual pada beberapa dekade belakangan ini yang mengkaji kultur matematika. Pertama, filsafat praktik matematika (philosophy of mathematical practice). Kedua, perubahan budaya dalam penelitian pendidikan matematika.

Sejauh ini, gerakan filsafat praktik matematika belum berbuat banyak untuk mengembangkan pendekatan-pendekatan kultural terhadap matematika. Filsuf dan sejarawan praktik matematika telah berupaya mengkaji apa yang dilakukan oleh matematikawan dan aktivitas yang mereka lakukan untuk menghasilkan matematika, tanpa memasukkan kultur atau pengertian terkait seperti masyarakat atau antarsubyektivitas. Selain itu, pendekatan kultural sama sekali tidak dibahas dalam buku terpenting do bidang filsafat praktik matematika pada beberapa tahun belakangan ini yang berjudul, "The Philosophy of Mathematical Practice", yang diedit oleh Mancosu. Padahal, tulisan-tulisan yang dikumpulkan dalam buku ini adalah representasi dari dari bidang-bidang kajian dalam filsafat praktik matematika. Pertanyaan kultural tentang bagaimana memasukkan nilai sosial dan reproduksi praktik belum banyak menjadi perhatian dalam seminar-seminar matematika.

Sebenarnya pada tahun 1950, Raymond L. Wilder telah menyatakan bahwa matematika, esensinya, adalah kultur. Mungkin karena dia memberikan pendekatan kultural sebagai jawaban terhadap pertanyaan metafisis 'apa itu matematika?', karya Wilder tidak secara langsung menstimulasi banyak pakar untuk mengambil idenya. Ini boleh jadi, karena makna budaya relatif kurang berdasarkan teori. Banyak pandangan dalam paparan Wilder yang berjudul, "Mathematics as a Cultural System”, tampaknya berasal dari pengalamannya sebagai seorang matematikawan kreatif, bukan karena pengaruh teori antropologi.

Raymond L. Wilder pun mungkin yang telah memberi pengaruh terhadap beberapa pakar, seperti Phillip J. Davis, Reuben Hersh, David Bloor dan mungkin juga Alvin White, yang telah mendirikan the Journal of Humanistic Mathematics dan selama bertahun-tahun 
menjadi editor pada jurnal ini. Hersh memasukkan beberapa pendekatan kultural atau antropologis dalam koleksinya yang berjudul, "Unconventional Essays on the Nature of Mathematics" yang diterbitkan oleh Springer pada 2006. Namun demikian, seperti yang ditulis oleh Hersh pada bagian pendahuluan bukunya bahwa kebanyakan artikel dalam koleksinya berbicara tentang aspek kognitif praktik matematika, bukan aspek kultural atau aspek sosial, dan ini merefleksikan kondisi gerakan filsafat praktik matematika ini.

Beberapa tahun belakangan, gerakan filsafat praktik matematika telah mulai menunjukkan interest yang lebih besar pada pendekatan kultural terhadap matematika dalam bentuk konferensi, termasuk konferensi yang diselenggarakan di Guangzhou, China, pada Nopember 2012 yang telah melahirkan buku, “Cultures of Logic and Mathematics”. Di Eropa, proyek the PhiMSAMP (Philosophy of Mathematics: Sociological Aspects and Mathematical Practice) berupaya mengkoneksikan penganut sosiologisme matematika dengan para sejarawan dan filsuf. Pada 2012-2014, London adalah tempat penyelenggaraan konferensi berseri ( 3 seri konferensi tentang kultur matematika). Dari presentasi-presentasi dalam serial konferensi ini, jelas bahwa konsep budaya relatif masih tidak dijadikan teori oleh para penulis tentang praktik matematika. Hanya sebagian kecil saja filsuf dan sejarawan dalam pertemuanpertemuan itu yang menyatakan makna budaya secara eksplisit. Salah satu pemakalah dalam pertemuan itu adalah Albrecht Heeffer. Ia mempresentasikan tentang the Abbaco Mathematical Culture dan dengan cermat ia memaparkan ide Alan Bishop tentang pembudayaan matematika (mathematical enculturation). Masalah kurangnya teori kultural dalam matematika adalah masalah yang serius. Hal ini karena praktik matematika cepat berubah. Namun demikian, pertentangan antara budaya manusia yang mudah berubah dan pencapaian matematika yang terus berlangsung merupakan masalah utama (standing problem) bagi pendekatan kultural terhadap matematika.

Ketika komunitas filsafat praktik matematika bergerak relatif lambat untuk menggunakan pendekatan kultural pada matematika, terjadi perubahan pada kultur dalam penelitian pendidikan matematika. Karen Francois, dalam video presentasinya pada "the cultures of logic and mathematics conference" di Guangzhou, menyampaikan sejarah singkat perkembangan penelitian pendidikan matematika. Sebelum 'perubahan kultural' (cultural turn) ini, penelitian pendidikan matematika kondisinya mirip dengan kondisi filsafat praktik matematika pada saat publikasi 18 Unconventional Essays, yang kebanyakan memfokuskan pada psikologi kognitif individu. Sekarang, penelitian pendidikan matematika mengikuti 'perubahan kultural' ini dan para peneliti dalam pendidikan matematika semakin mengkaji pembelajaran dan pengajaran matematika sebagai aktivitas kultural. 


\section{Etnomatematika sebagai Aspek Kultural Matematika}

Di Indonesia perubahan kultural penelitian pendidikan matematika kian terasa. Dalam dekade terakhir, pendekatan kultural pada matematika kian marak disosialisasikan dan cukup mewarnai sejumlah jurnal di Indonesia. Bahkan, Program Pascasarjana (PPs) Universitas Negeri Yogyakarta telah merilis "Ethnomathematics Journal", di mana Editor-in-Chief dari jurnal ini adalah Prof. Dr. Marsigit, M.A, guru besar dalam bidang filsafat matematika Universitas Negeri Yogyakarta. Nama jurnal ini memberi kesan terhadap aspek kultural matematika sebagai fokus utama tulisan yang dimuat dalam jurnal ini (Graduate School Universitas Negeri Yogyakarta, 2020).

Bidang etnomatematika menghubungkan cara mengetahui dan belajar yang beragam dari siswa melalui penggunaan pengetahuan yang dilekatkan pada kultur dan kurikulum matematika. Pendekatan tentang kurikulum matematika ini mengeksplorasi cara akademik dan cara yang kaya secara kultural untuk memberikan program pengembangan yang lebih inklusif bagi populasi yang beragam pelayanan dalam institusi pendidikan. Dalam hal ini, etnomatematika adalah suatu program yang mencakup relevansi kurikuler dan membangun pengetahuan tentang interest lokal, kebutuhan dan kultur siswa. Dengan kata lain, etnomatematika sebagai suatu metodologi pengajaran didesain agar sesuai dengan kultur sekolah di mana siswa berada sebagai basis untuk membantu mereka saling memahami, mengembangkan dan menstrukturkan interaksi sosial, dan mengkonseptualisasikan pengetahuan matematika. Dengan memperkenalkan perspektif ini dalam kurikulum matematika, pendidikan dan guru melibatkan imajinasi siswa; membantu mereka mengembangkan skill analisis dan berpikir kritis yang dapat diterapkan ke semua bidang kehidupan, dan memberikan lingkungan yang efektif untuk mengembangkan skill dalam memecahkan masalah dunia nyata (Rosa \& Orey, 2011).

Etnomatematika membantu siswa belajar matematika dan membuat koneksi pelajaran di sekolah ini dengan pengetahuan dan pengalaman siswa sebelumnya. Pengajaran matematika melalui pengalaman personal dan relevan dengan kultur membantu siswa mengetahui lebih banyak tentang realitas, kultur, masyarakat, isu lingkungan, dan diri mereka sendiri. Dalam perspektif ini, siswa mengembangkan pemahaman yang dalam tentang matematika dan meningkatkan daya serp terhadap konsep matematika formal dengan menerapkan etnomatematika. Dengan kata lain, perspektif etnomatematika dalam kurikulum matematika mendukung pengenalan metode pengajaran yang relevan dengan kultur yang menantang apa yang disebut Eurosentrisme pendidikan matematika. Perspektif ini juga mendukung bahwa perlu mengajarkan matematika kepada siswa dengan cara yang bermakna secara kultural dan 
historis. Pendekatan etnomatematika dalam kurikulum matematika dianggap sebagai kendaraan pedagogi untuk mencapai tujuan pembelajaran matematika (Rosa \& Orey, 2011).

\section{Karakteristik Kultural Matematika}

Kultur matematika dapat disebut sebagai himpunan nilai, konvensi, atau praktik sosial yang berkaitan dengan matematika. Karakteristik kultural matematika dilihat dari nilai, konvensi dan praktik sosialnya adalah sebagai berikut.

Pertama, nilai dan praktik sosial. Selama bertahun-tahun matematika dianggap sebagai disiplin ilmu yang netral dan bebas kultur dari nilai sosial. Saat itu, matematika selalu diajarkan di sekolah sebagai pelajaran yang bebas dari budaya yang dalam pembelajaran hanya melibatkan fakta, konsep dan prinsip matematika yang diterima secara universal. Padahal matematika itu adalah budaya. Program etnomatematika (oleh Ubiratan D' Ambrosio) dikembangkan untuk melawan pernyataan bahwa matematika adalah bidang kajian yang universal dan tidak terkait kultur (Rosa \& Orey, 2011). Selain itu, ada perkataan dari Hans Freudenthal (penggagas Realistic Mathematics Education) yang merupakan kredo pendidikan matematika beliau, “mathematics as human activity" (Gravemeijer \& Terwel, 2000). Ini berarti bahwa karakteristik kultural matematika adalah sarat nilai dan praktik sosial.

Kedua, konvensi. Matematika adalah ilmu yang memiliki banyak wajah, di mana tidak ada kesepakatan di antara para matematikawan tentang apa itu matematika (Johnson \& Rising, 1967; Hudojo, 1990; Soedjadi, 2000), sejak masa Yunani klasik sampai saat ini. Artinya, definisi yang dikemukakan berdasarkan pada pemikiran atau sudut pandang filosofis tertentu saja. Namun demikian, definisi yang berbeda-beda itu, bila didalami akan menunjukkan karakteristik tertentu yang dapat merangkum definisi matematika secara umum (Soedjadi, 2000). Menurutnya, ada setidaknya enam karakteristik yang dapat merangkum definisi matematika, yaitu memiliki objek abstrak, bertumpu pada kesepakatan, berpola pikir deduktif, memiliki simbol yang kosong dari arti, memperhatikan semesta pembicaraan, dan konsisten dalam sistemnya. Bagi kami, karakteristik yang dikemukakan oleh Soedjadi (2000) sejatinya adalah konvensi di kalangan matematikawan. Ini adalah karakteristik kultural matematika yang sarat akan konvensi yang merupakan tumpuan yang amat penting dalam matematika.

\section{Karakteristik Filosofi Matematika}

Uraian pada bagian ini adalah sintesis dari dua bab awal pada bagian pertama dari karya Ernest (1991). Oleh karena itu, pembaca yang ingin melihat uraian detail tentang diskusi ini, silakan merujuk ke Ernest (1991) tersebut. Secara singkat, bagian ini kami paparkan sebagai berikut.

Dalam merekonseptualisasi filsafat matematika, matematikawan meninjau kembali hal- 
hal yang harus dicakup oleh sebuah filsafat untuk bisa dianggap sebagai filsafat matematika, karena matematika itu mencakup banyak segi, dengan sebuah tubuh pengetahuan proposisi. Dengan tubuh pengetahuan proposisi tersebut, matematika dapat dideskripsikan berdasarkan konsep, karakteristik, sejarah dan praktiknya. Kompleksitas filsafat matematika harus mencakup kompleksitasnya dan memuat jawaban terhadap beberapa pertanyaan berikut. Apakah manfaat matematika? Apakah peranan umat manusia dalam matematika? Bagaimanakah mengubah pengetahuan subjektif seseorang menjadi pengetahuan matematika yang objektif? Bagaimanakah pengetahuan matematika itu berkembang? Bagaimanakah sejarah pengetahuan matematika menjelaskan filsafat matematika? Bagaimanakah hubungan antara matematika dan bidang pengetahuan lain, serta pengalaman manusia? Mengapa teori matematika murni dianggap sudah terbukti bermanfaat melalui aplikasinya pada masalah sains dan masalah praktis? Sejumlah pertanyaan tersebut merepresentasikan suatu perluasan lingkup filsafat matematika dari perhatian absolutisme yang bersifat internal.

Saat dilakukan rekonseptualisasi, peran filsafat matematika adalah mendeskripsikan sifat matematika yang mencakup bukan hanya persoalan epistemologi dan ontologi 'internal', seperti justifikasi pengetahuan matematika, tetapi juga persoalan 'eksternal', seperti sejarah, genesis, dan pelaksanaan (praktik) matematika. Dengan demikian, suatu filsafat matematika mestinya melingkupi kriteria berikut: (a) pengetahuan matematika: sifat, justifikasi dan genesisnya; (b) obyek-obyek matematika: sifat dan asal-usulnya; (c) aplikasi matematika: keefektifannya dalam sains, teknologi dan bidang-bidang lainnya; dan (d) pelaksanaan (praktik) matematika: berbagai aktivitas para matematikawan, baik di masa sekarang maupun di masa lampau. Kriteria tersebut merepresentasikan suatu rekonseptualisasi peranan filsafat matematika. Setelah rekonseptualisasi, filsafat matematika berperan merepresentasikan tugas filsafat matematika secara tepat. Maksudnya, merepresentasikan tugas yang telah dikaburkan oleh identifikasi yang keliru tentang filsafat matematika dengan fondasi yang logis tentang pengetahuan matematika. Adanya kriteria di atas, berarti terbuka jalan untuk menguji layak tidaknya suatu aliran itu diterima, untuk selanjutnya bisa dianggap sebagai filsafat matematika.

Filsafat matematika direkonseptualisasi dengan menguji beberapa aliran filsafat berdasarkan 4 (empat) kriteria di atas untuk mengetahui kelayakan suatu filsafat dianggap sebagai filsafat matematika. Di antara aliran filsafat yang masuk dalam daftar pengujian adalah tiga aliran absolutis yang dinyatakan telah gagal mempertahankan kepastian matematika, yaitu logisisme, formalisme dan intuisionisme (konstruktivisme). Selain aliran itu, aliran filsafat yang turut diuji adalah platonisme, konvensionalisme, dan Empirisisme. Hasil pengujian terhadap aliran-aliran tersebut berdasarkan 4 (empat) kriteria ketercukupan menunjukkan bahwa quasi- 
empirisisme memenuhi 3 (tiga) dari 4 (empat) kriteria, yaitu: pengetahuan matematika (i), aplikasi matematika, (iii) dan praktik matematika (iv) Quasi-empirisisme Lakatos jauh melebihi aliran yang lain, termasuk jika ditinjau dari segi ruang lingkupnya.

Lakatos mengemukakan kesalahan pengetahuan matematika dan menguraikan teori genesisnya. Dengan itu, dia bisa melakukan inklusi praktik-praktik matematika beserta sejarahnya. Kekuatan utama filsafat matematika Lakatos terletak pada sifatnya yang deskriptif atau tidak preskriptif. Maksudnya, mendeskripsikan matematika apa adanya, tanpa menjadikannya sebagai sesuatu yang harus dipraktikkan. Dalam quasi-empirisisme, Lakatos membuat cakupan yang lebih luas (ekstensif) daripada filsafat-filafat lainnya, sehingga dapat dikatakan bahwa quasi-empirisisme bergantung pada rekonseptualisasi dan redefinisi Lakatos tentang filsafat matematika. Lakatos menghindari penggunaan ortodoksi fondasionisme dan absolutisme filsafat matematika. Dengan jalan ini, Lakatos telah membebaskan filsafat matematika dari peninjauan kembali terhadap fungsinya. Meskipun ia masih mempertanyakan status kebenaran matematika yang tidak boleh ditentang

\section{Kesimpulan}

Berdasarkan uraian di atas, dapat dikatakan bahwa karakteristik kultural dan filosofi matematika adalah sebagai berikut.

Karakteristik kultural matematika dapat dilihat dari sisi nilai dan praktik sosial matematika. Nilai kultural matematika dapat dilihat dari program etnomatematika yang digagas oleh Ubiratan D' Ambrosio. Etnomatematika telah menggugurkan asumsi bahwa matematika tidak terkait kultur. Sementara itu, kredo pendidikan Hans Freudenthal bahwa matematika adalah aktivitas manusia melalui Realistic Mathematics Education tampaknya telah menggugurkan asumsi bahwa matematika tidak terkait dengan praktik sosial matematika. Namun demikian, tetap diakui bahwa matematika memiliki karakteristik yang khas atau sifat alami sebagai suatu konvensi, yaitu memiliki objek abstrak, bertumpu pada kesepakatan, berpola pikir deduktif, simbolnya kosong dari arti, perhatian terhadap semesta pembicaraan dan konsistensi dalam sistemnya.

Karakteristik filosofi matematika bergantung pada sudut pandang aliran-aliran filsafat tertentu terhadap matematika. Secara umum, saat ini ada dua aliran besar dilihat dari epistemologi matematika, yaitu absolutisme matematika dan fallibilisme matematika. Hasil rekonseptualisasi filsafat matematika menunjukkan bahwa suatu filsafat matematika mestinya memenuhi empat kriteria, yaitu: a) pengetahuan matematika: sifat, justifikasi dan genesisnya; b) obyek-obyek matematika: sifat dan asal-usulnya; c) aplikasi matematika: keefektifannya 
dalam sains, teknologi dan bidang-bidang lainnya; dan d) praktik matematika: berbagai aktivitas para matematikawan, baik di masa sekarang, maupun di masa lampau.

\section{DAFTAR PUSTAKA}

Ernest, P. 1991. The Philosophy of Mathematics Education. London: Routledge-Falmer.

Elmer E. Rasmuson Library. (2020). Library Research Process (online). (https://library.uaf.edu/ls101-research-process) diakses pada 4 April 2021

Gie, T. L. 1993. Filsafat Matematika Bagian Kedua Epistemologi. Yogyakarta: Yayasan Studi Ilmu dan Teknologi.

Graduate School Universitas Negeri Yogyakarta, 2020. Ethnomathematics Journal (online) (https://journal.uny.ac.id/index.php/ethnomath/index) (Diakses pada Ahad, 18 Oktober 2020).

Gravemeijer, K. \& Terwel, J. 2000. Hans Freudenthal: a Mathematician on Didactics and curriculum theory, Journal of Curriculum Studies, 32(6): 777-796.

Hanna, G. 1983. Rigorous Proof in Mathematics Education. Toronto: The Ontario Institute for Studies in Education.

Hudojo, H. 1990. Belajar Mengajar Matematika. Malang: IKIP Malang Press.

Johnson, D. A. \& Rising, G. R. 1967. Guidelines for Teaching Mathematics. California: Wadsworth Publishing Company, Inc.

Khait, A. 2005. The Definition of Mathematics: Philosophical and Pedagogical Aspects, Science \& Education, 14: 137-159.

Larvor, B. 2016. What Are Mathematical Cultures? Dalam S. Ju et al. (eds.), Cultures of Mathematics and Logic, Trends in the History of Science, (Hal. 1-22).

Merriam-Webster Dictionary. 2020. Culture. (online) (https://www.merriamwebster.com/dictionary/culture) (Diakses pada 15 April 2020).

Rosa, M. \& Orey, D. C. 2011. Ethnomathematics: the cultural aspects of mathematics. Revista, Latinoamericana de Etnomatemática, 4(2): 32-54.

Skemp, R. R. 1987. The Psychology of Learning Mathematics (Expanded American Edition). New Jersey: Lawrence Erlbaum Associates, Publishers.

Soedjadi, R. 2000. Kiat Pendidikan Matematika di Indonesia: Konstatasi Keadaan Masa Kini menuju Harapan Masa Depan. Jakarta: Depdiknas. 